\title{
Consumer Behaviour during Pandemic of COVID-19
}

\section{Lenka Svajdova}

Ing. Bc, Ph.D. Assistant Professor, Technical University of Ostrava Department of Marketing and Business, Czech Republic.

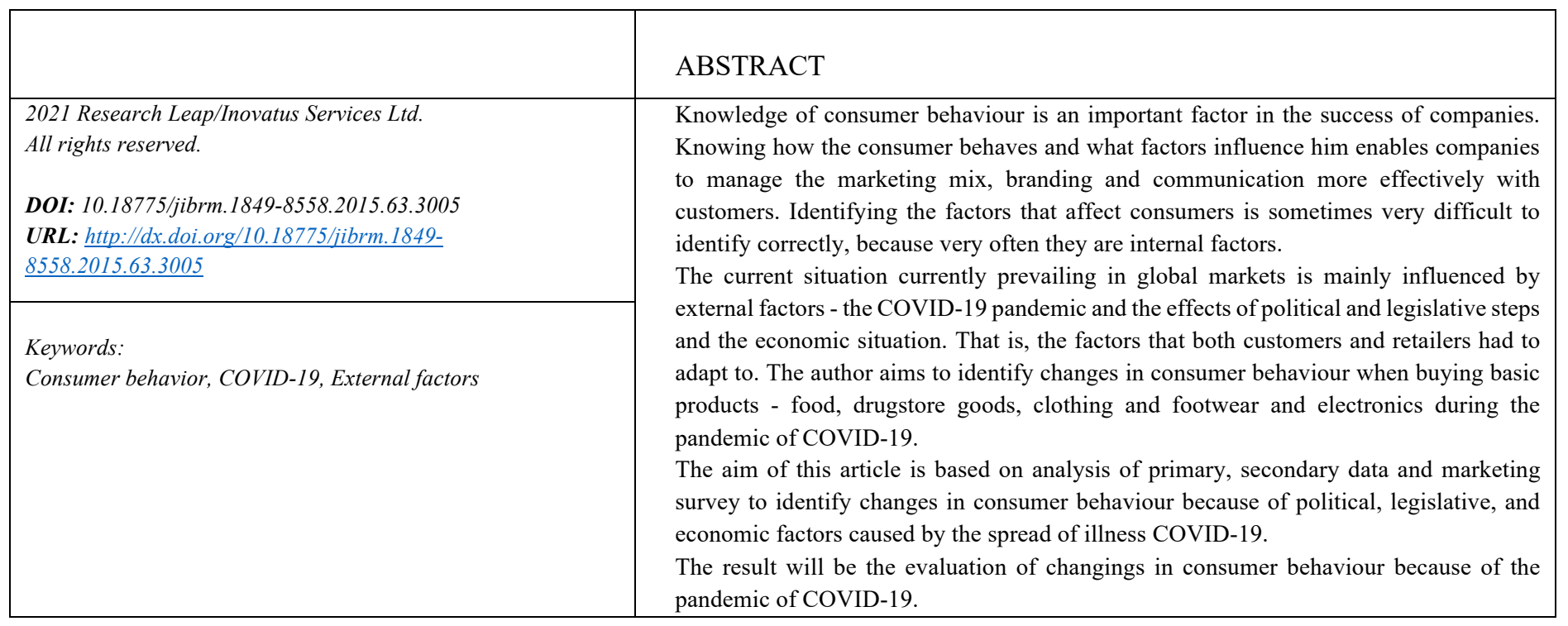

\section{Introduction}

The year 2020 will go down in the history of retail as a year of overcoming problems and opening new possibilities. One of the benefits of an otherwise unfavourable situation is the fact that customers have begun to realize how important retail is to their daily lives.

Covid-19 has changed the world of retail and the customer. Based on the comparison with the previous period, there was an increase in average spending and a decrease in the frequency of purchases. Consumer confidence has fallen; people are worried about the future. Retailers have invested billions in anticoronary measures and E-commerce is breaking records.

The coronavirus pandemic has changed customers' shopping behaviour in addition to the pandemic itself, there were also influences based on political, legislative, and economic factors. The shopping basket has changed, the routine of running households, the reasons for purchasing and the availability of goods and services have changed. Whether the changes will be permanent, or everything will return to its original state will be shown in the next months and will be the subject of research that will follow the research mentioned in this article

\section{Consumer Behaviour}

Zamazalová (2008) talks about internal and external factors influencing consumer behaviour. Among the external factors, the marketing macro environment is mentioned, which influences the implementation and development of marketing activities that are aimed at target customers.

The environment is constantly changing very fast. External factors that influence consumer behaviour create the following groups of factors: social factors (further divided into demographic and cultural factors), technical and technological factors, economic factors, political and legal factors (legislative framework) and natural factors.

Douchova et al. (1993) considers the following to be the most important factors influencing consumer behaviour: objective conditions of consumer behaviour (individual economic environment and objective economic situation) and consumer personality, his social environment and situational tuning.

\subsection{Consumer Behaviour and COVID-19}

This turbulent situation has huge impact on everyday consumers' life. The pandemic of COVID - 19 has significantly dramatically changed both the businesses acting and consumers behaving (Donthu and Gustafsson, 2020; Pantano et al., 2020). 
Laato et al. (2020) underline that the government prepared lockdown by closing schools, restaurants, some shops, and public services, which may have spread fears of what will happen in future. Due to this fact it is also possible to consider that customers will change their shopping habits in the long run. For example, Sheth (2020) claims that there are four major contexts which govern or disrupt consumer habits. They are social context (e.g., changes in the workplace and in interaction with neighbours and friends), the implementation of new technology (including online shopping and delivery), the impact of consumption habits due to new rules (the COVID-19 pandemic regulations), and less predictable context (the development of the global COVID-19 pandemic).

Kirk and Rifkin (2020) that history shows that a period of crisis can and is often perceived as an impetus for significant transformations in society. and recommend paying attention to consumer behaviours in each of these three phases: reacting, coping, do-it-yourself behaviours, and then also longer-term adapting.

The change in consumer behaviour identified in this article was the COVID-19 pandemic. Which from the point of view of theoretical background we can consider as an external factor belonging to the group of natural factors, however, complementary factors that influenced consumer behaviour were, according to the author, political and legislative factors, and economic factors, which were represented by restrictions and uncertainty caused by concerns about the economic future.

\subsection{Methodology}

The questionnaire survey method will be used to achieve the goals of this article. The questionnaire survey take place online and the method of personal interviewing. The selection file will contain 414 respondents to be selected. To obtain relevant data, the random selection will be used to select the sample this guarantee maximum representativeness of the research. The selection will contain the entire structure of the surveyed file considering the age. The aim of the questionnaire survey will be to identify changes in consumer purchasing behaviour due to the COVID 19 pandemic, with a special focus on changes in the way of purchasing goods like time, place and method of purchase compared to the "pre-covid" period.

The questionnaire survey was carried out between December 2020 and January 2021. The total number of 424 respondents from the Moravian-Silesian Region (Czech Republic) participated in the questionnaire survey. After the proof of survey in pilotage, the questionnaire was carried out online and by personal interviewing. Of the 414 respondents, 318 were women and 106 were men. There were 49 respondents in the 15 25 age group. From 26- 35 years old group were 85 respondents. Between the ages of 36 and 45 there were 86 interviewees. The age of 46 and 55 was represented by 71 respondents. And between the ages of 56 and 65 there were 80 responders, and the age group of $65+$ was represented by 53 responders. The aim of the research was not to identify the causes, but descriptive - to identify changes that consumers had noticed about their behaviour. In order to obtain comprehensive results of the impact of COVID 19 on consumer purchasing behaviour, questions were divided into four areas of questions - food purchases, drugstores, fashion and footwear and electronics. So, two sectors where there were no bans and two that were affected by authorities' restrictions. The period for which respondents described their shopping habits was October 2020 to January 2021. Thus, a period that was largely affected by the effects of government restrictions on the retail sector for a smaller part of this period took place under a looser regime.

\section{Survey}

The author will continue with presenting the results of the survey and will compare those results with data from the survey published in Retail's news journal containing data related to ecommerce. The implemented questionnaire survey was focused on confirming the observed changes in consumer behaviour when buying food, drugstore goods, clothing and footwear and electronics. The questions were aimed at identifying possible changes in the frequency of purchases, changes in the composition of purchases, e-shop preferences and shopping time for food and drugstore goods, the retail units of which were not restricted in any way. In the case of clothing, footwear, and electronics, it was found out how big a problem for consumers was the closure of stores and the rate of use of e-shops in obtaining these goods.

For each sector, several statements were made with which the respondent had to express his / her level of agreement. The level of agreement was to consider a comparison of purchasing behaviour before the start of the COVID-19 Pandemic.

\subsection{Consumer Behaviour - Food}

Observing the Figure 1 it can be declared that when excluding respondents who were unable to assess the degree of agreement /disagreement with the statement, half of the respondents expressed the opinion that they did not change the time of shopping. In the case of food, there was no outflow of customers to the online space, $40 \%$ of respondents started buying food in e-shops to a greater extent than before the COVID-19 pandemic. More than $50 \%$ of respondents look forward to reopening farmers' markets. 64\% remained loyal to shops when buying food. More than half of the 414 respondents did not change their shopping cart. About half then changed the frequency of their purchases. This corresponds to the results of research at the national level.

E-shops began to be used to a greater extent by respondents in the age group 15 to 35 and to a greater extent by men who were represented in this age group. The time of purchase was changed rather by economically active residents. 


\section{Consumer Behaviour - Food}

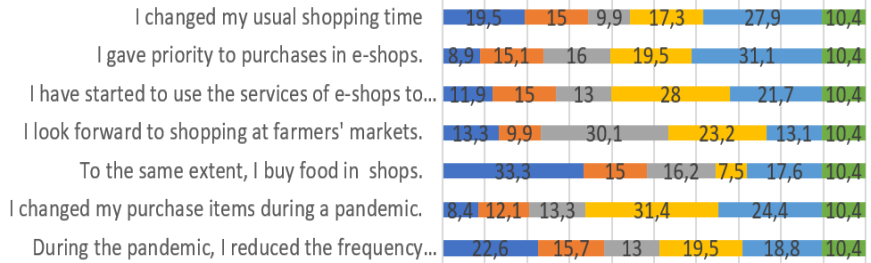

0\% 10\% 20\% 30\% 40\% 50\% 60\% 70\% 80\% 90\% $100 \%$
Figure 1: Consumer Behaviour - Food Source: Author's research

\subsection{Consumer Behaviour - Drugstore}

As for changing in consumer behaviour purchasing drugstore (Figure 2 Consumer behaviour - Drugstore) there were no surprises. Respondents didn't show preferences for e-shops, they continued in purchasing these kinds of products in shops and didn't change timing of shopping. What have changed was the frequency of shopping - they visited those shops with less frequency and the products were different.

E-shops began to be used to a greater extent by respondents in the age group 25 to 35 and to a greater extent by women who were represented in this age group.

\section{Consumer Behaviour - Drugstore}

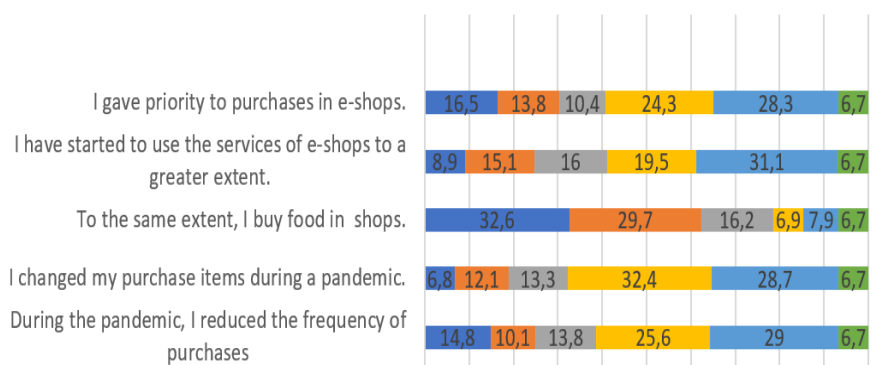

$0 \% 10 \% 20 \%$ 30\% $40 \%$ 50\% $60 \%$ 70\% $80 \% 90 \% 100 \%$

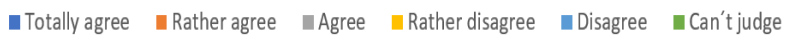

Figure 2: Consumer Behaviour - Drugstore

Source: Author's research

\subsection{Consumer Behaviour - Clothes and Shoes}

Clothing stores and shoes stores were affected by restrictions and bans to stop spreading the virus. For more than $73 \%$ of respondents the closing of stores of clothes and shoes was a significant problem and led to a reduction in demand for this kind of products. In age group less than 45 the usage of e-shop is significant, in the age group between $15-25$ the number of eshoppers is the same.
Consumer Behaviour - Footwear and Fashion

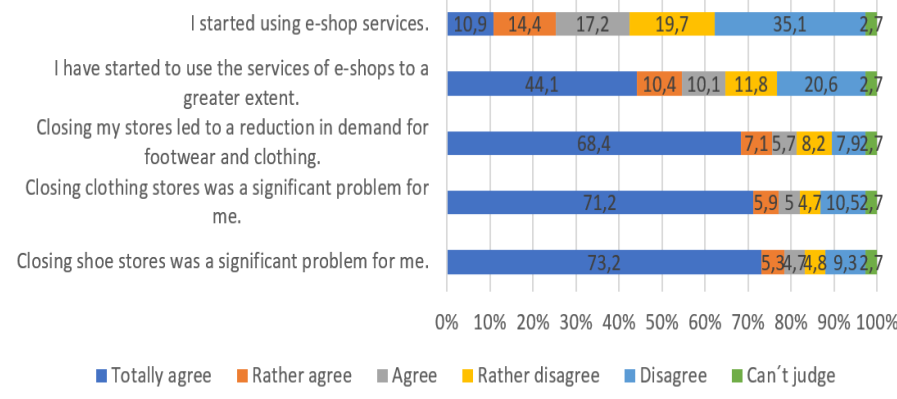

Figure 3: Consumer Behaviour - Footwear and Fashion Source: Author's research

\subsection{Consumer Behaviour - Electronics}

Almost $70 \%$ of respondents agreed on a fact, that closing of stores with Electronics represented significant problem to them and $41 \%$ of them used e-shop for the first time and almost $50 \%$ used e-shop with more frequency. More than $70 \%$ declared that the close of the store led to decrease in demand. The close of shops was bigger problem for the age group 55+, and the age group $45+$ started to use e-shops for purchasing electronics.

\section{Consumer Behaviour - Electronics}

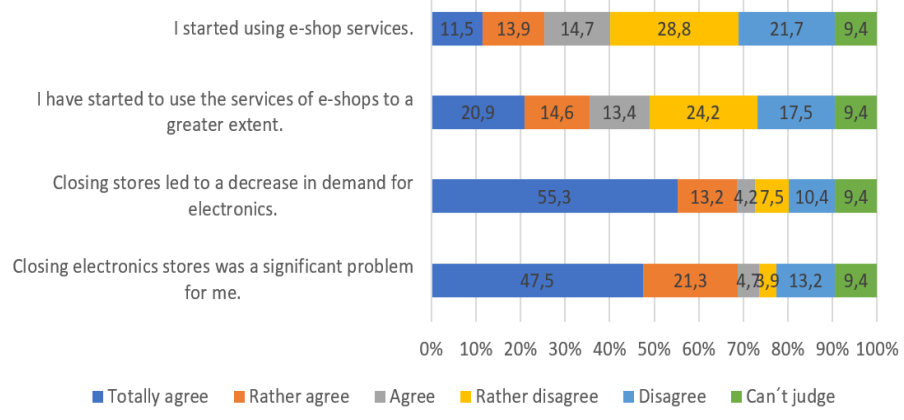

Figure 4: Consumer Behaviour - Electronics Source: Author's research

\section{Discussion}

Since the beginning of the first outbreak of COVID-19 in early 2020, consumer behaviour has deviated significantly from normal. Closing stores combined with consumers' fear of their own health has led to an immediate and sharp increase in demand and the use of alternative distribution channels.

Coronavirus has changed consumer behaviour in every way. During an emergency, more than $37 \%$ of customers shopped online than usual. Even after its completion, e-shops are used by $23 \%$ of shoppers more than before government restrictions. According to estimates by the Association for Electronic Commerce (APEK), the turnover of e-shops in the preChristmas period alone could reach CZK 65 billion, which means a year-on-year growth of more than $25 \%$. However, the result in this complicated year will be influenced by several factors, including the willingness of people to spend. The estimated year-on-year growth of online retail compared to 
2019 is about $25 \%$, which would mean more than CZK 190 billion in total turnover, according to APEK (Retail news, 2021). The unprecedented situation that 2020 brought a number of changes. And so internet sales are even higher than even the most optimistic expectations. At the same time, however, it is necessary to emphasize that this success did not fall entirely into the lap of e-shops alone. The readiness and capabilities of Czech online store operators have been and are crucial (Retailnews, 2021).

The discussion could be set on the fact if the changes in consumer behavior as for ,adiction" for on-line shopping will be permanent or it will decrease in the post-COVID times.

\section{Conclusion}

Based on the research, it can be concluded that there has been a change in consumer behaviour in the Czech Republic because of restrictions that have been introduced to reduce the spread of COVID-19. In all analysed sectors - sales of food, drugstore goods, clothing and footwear, electronics, there was an increase in sales volumes through online channels. For drugstore goods and food, there was a change in the structure of purchases and the frequency of purchases. Demand for clothing, footwear, and electronics, which were closed due to government measures, decreased, despite a growing number of online purchases. The question remains whether the changes will be permanent, or customers will return to their original shopping habits.

\section{Literature}

- Douchová, J., Komárková, R., Mejtská, D., Rymeš, M., Vysekalová, J. (1993). Základy psychologie trhu. Praha: H \&H

- Donthu, N., Gustafsson, A., (2020). Effects of COVID-19 on business and research. J. Bus. Res. CrossRef

- $\quad$ Kirk, C.P., Rifkin, L.S., (2020). I'll trade you diamonds for toilet paper: consumer reacting, coping and adapting behaviors in the COVID-19 pandemic. J. Bus. Res. CrossRef

- $\quad$ Laato, S., Islam, N.A.K.M., Farooq, A., Dhir, A., (2020). Unusual purchasing behavior during the early stages of the COVID-19 pandemic: the stimulus-organism-response approach. J. Retailing Consum. Serv. CrossRef

- Pantano, E., Pizzi, G., Scarpi, D., Dennis, Ch, (2020). Competing during a pandemic? Retailers' ups and downs during the COVID19 outbreak. J. Bus. Res. CrossRef

- Dolgui, A. \& Proth, J. (2013). Outsourcing: Definitions and analysis. International Journal of Production Research. Abingdon, England. Taylor \& Francis Group. CrossRef

- Sheth, J., (2020). Impact of Covid-19 on consumer behavior: will the old habits return or die? J. Bus. Res. $\underline{\text { CrossRef }}$ 